\title{
Antitumor efficacy of sequential treatment with docetaxel and 5-fluorouracil against human oral cancer cells
}

\author{
TETSUYA TAMATANI, TARANNUM FERDOUS, NATSUMI TAKAMARU, KANAE HARA, \\ MAKOTO KINOUCHI, NOBUYUKI KURIBAYASHI, GO OHE, DAISUKE UCHIDA, \\ HIROKAZU NAGAI, KENJI FUJISAWA and YOUJI MIYAMOTO
}

\begin{abstract}
Department of Oral Surgery, Subdivision of Molecular Oral Medicine, Division of Integrated Sciences of Translational Research, Institute of Health Biosciences, The University of Tokushima Graduate School, Tokushima 770-8504, Japan
\end{abstract}

Received March 12, 2012; Accepted May 17, 2012

DOI: 10.3892/ijo.2012.1544

\begin{abstract}
Docetaxel (DOC) and 5-fluorouracil (5-FU) are important anticancer agents widely used in the treatment of a variety of cancers including oral squamous cell carcinoma (OSCC). The purpose of this study was to determine the antitumor efficacy of the sequential administration of DOC and 5-FU against OSCC cells (B88 and CAL27 cells) in vitro and in vivo. In in vitro growth inhibition assays, sequential treatment with DOC followed by 5-FU was more effective in inhibiting cancer cell growth than 5-FU followed by DOC, single treatment with DOC or 5-FU, or combined treatment with DOC and 5-FU. Furthermore, DOC followed by 5-FU significantly inhibited tumor growth in vivo compared to 5-FU followed by DOC. To understand the mechanisms underlying the enhanced growth inhibitory effect of the administration sequence, DOC followed by 5-FU, we examined the expression of 5-FU metabolic enzymes such as thymidylate synthase (TS), dihydropyrimidine dehydrogenase (DPD) and orotate phosphoribosyl transferase (OPRT), which were known to regulate the antitumor effect of 5-FU, by real-time RT-PCR and western blot analysis. Downregulation of TS and DPD expression and upregulation of OPRT expression were induced by DOC treatment, suggesting that DOC enhanced the efficacy of 5-FU by altering the expression of its metabolic enzymes. These results indicate that sequential treatment with DOC followed by 5-FU could be a promising therapeutic strategy for oral cancer.
\end{abstract}

\section{Introduction}

A variety of treatments have been used for oral squamous cell carcinoma (OSCC), including surgery, radiotherapy, and

Correspondence to: Dr Tetsuya Tamatani, Department of Oral Surgery, Subdivision of Molecular Oral Medicine, Institute of Health BioSciences, The University of Tokushima Graduate School of Dentistry, 3-18-15 Kuramoto-cho, Tokushima 770-8504, Japan

E-mail: ttama@dent.tokushima-u.ac.jp

Key words: oral squamous cell carcinoma, 5-fluorouracil, docetaxel, sequential treatment, 5-fluorouracil metabolic enzymes chemotherapy administered alone or in combination. For patients with locally advanced OSCC that were unresponsive to induction chemotherapy (1-3), new chemotherapeutic treatment strategies are needed for improving the treatment outcome and cure rates (4-6).

5-Fluorouracil (5-FU) is widely used as an anticancer agent and considered a key drug in chemotherapeutic treatments for OSCC, colorectal, gastric, and oesophageal cancer (5-8). Thymidylate synthase (TS), dihydropyrimidine dehydrogenase (DPD), and ortate phosphoribosyl transferase (OPRT) are key enzymes in the regulation of 5-FU metabolism (9). Two main action mechanisms have been proposed for 5-FU through its active metabolites, 5-fluorodeoxyuridine monophosphate (FdUMP) and 5-fluorouridine triphosphate (FUTP) (Fig. 1), with the main mode of action being through FdUMP (10). FdUMP suppresses TS by forming covalent ternary complexes with 5,10-methylenetetrahydrofolate $\left(\mathrm{CH}_{2} \mathrm{THF}\right)$, which then inhibits DNA synthesis. RNA function is inhibited when 5-FU is modified by OPRT to form 5-fluorouridine monophosphate (FUMP), which is then converted to FUTP. FUTP is incorporated into cellular RNA, resulting in RNA dysfunction. Thymidine phosphorylase (TP) anabolizes 5-FU to FdUMP. DPD is the initial enzyme in the catabolism of 5-FU to 2 -fluoro- $\beta$-alanine, primarily in the liver. DPD is also the rate-limiting enzyme of 5-FU catabolism, degrading $85 \%$ of the administered dose of 5-FU into inactive metabolites (10). Therefore, downregulation of TS and DPD expression and upregulation of OPRT expression enhance the anti-tumor effect of 5-FU (9-12). Hence, the pharmacogenetic variability of these enzymes might be a major determinant of the variations in outcome among cancer patients treated with 5-FU (9). The relative expression levels of the TS, DPD, and OPRT genes were reported as a predictive factor for the prognosis and survival of oral cancer patients treated with 5-FU $(13,14)$.

DOC is also an effective agent against OSCC (15). We selected DOC as the combination agent in this study because of its overlapping antitumor spectrum including breast, oesophageal, gastric, and oral cancers $(15,16)$. Additionally, DOC has a different mechanism of action from 5-FU and acts as a potent anti-mitotic agent by promoting abnormal microtubule stabilization, which results in inhibition of mitosis between metaphase and anaphase, and in the initiation of apoptosis (17). 


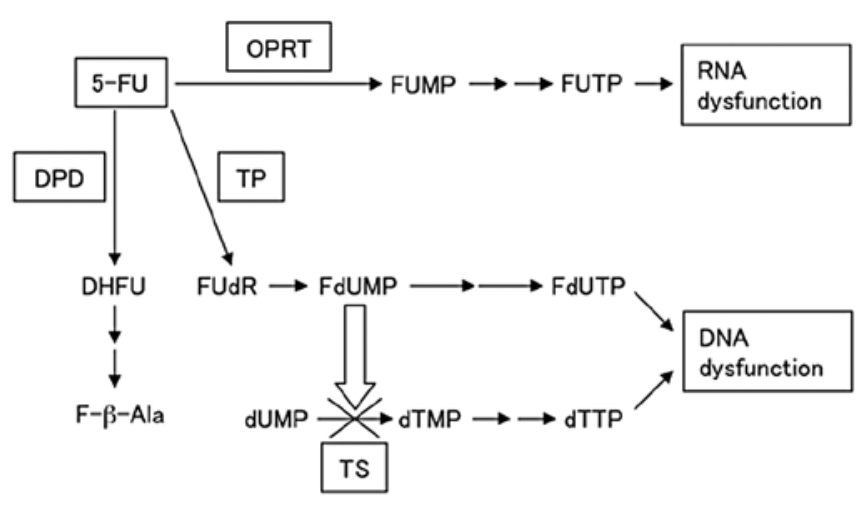

Figure 1.5-FU,metabolic pathway of 5-fluorouracil;OPRT, ortate phosphoribosyl transferase; FUMP, 5-fluorouridine monophosphate; FUTP, 5-fluorouridine triphosphate; TP, thymidine phosphorylase; FUdR, 5-fluorodeoxyuridine; FdUMP, 5-fluorodeoxyuridine monophosphate; FdUTP, 5-fluorodeoxyuridine triphosphate; TS, thymidylate synthase; dUMP, deoxyuridine monophosphate; dTMP, deoxythymidine monophosphate; dTTP, deoxythymidine triphosphate; DPD, dihydropyrimidine dehydrogenase; DHFU, 5-fluoro-dihydrouracil; F-b-Ala, a-fluoro-b-alanine.

The combined treatment of 5-FU and DOC has been reported to improve response rates $(14,15)$, however, little is known about sequential treatment with DOC and 5-FU.

The aim of this study was to evaluate the anti-tumor effects of sequential treatment with DOC and 5-FU against OSCC. Furthermore, to elucidate the mechanisms underlying the enhanced growth inhibitory effect of DOC followed by 5-FU, we examined the expression of the 5-FU metabolic enzymes TS, DPD and OPRT.

\section{Materials and methods}

Cell lines and cell culture. B88 cells were previously established from an OSCC patient in our laboratory (18). CAL27 cells were obtained from American Type Culture Collection (Rockville, MD, USA). Both cell lines produce tumors when subcutaneously inoculated into nude mice. The cells were cultured and maintained in Dulbecco's modified Eagle's medium (DMEM) (Sigma Aldrich Co., St. Louis, MO, USA) supplemented with $10 \%$ fetal bovine serum (FBS) and $5 \%$ antibiotic-antimycotic solution in a humidified atmosphere containing $5 \% \mathrm{CO}_{2}$ at $37^{\circ} \mathrm{C}$.

In vitro cell growth assay. Cells $\left(3 \times 10^{3}\right.$ cells per well) were seeded in 96-well plates. Twenty-four hours later, cells were treated with various concentrations of 5-FU or DOC for $24 \mathrm{~h}$. Then, they were treated either with sequential treatment, $100 \mathrm{pg} / \mathrm{ml}$ DOC for $24 \mathrm{~h}$ followed by $4 \mu \mathrm{g} / \mathrm{ml} 5-\mathrm{FU}$ for $24 \mathrm{~h}, 4 \mu \mathrm{g} / \mathrm{ml} \mathrm{5-FU}$ for $24 \mathrm{~h}$ followed by $100 \mathrm{pg} / \mathrm{ml}$ DOC for $24 \mathrm{~h}$ or with combined treatment, $4 \mu \mathrm{g} / \mathrm{ml} 5-\mathrm{FU}$ and $100 \mathrm{pg} / \mathrm{ml}$ DOC at the same time for $48 \mathrm{~h}$. A $10 \mu \mathrm{l}$ aliquot of $5 \mathrm{mg} / \mathrm{ml} \mathrm{3-(4,5-dimethylthiaol-2-yl)-2,5-diphen-}$ yltetrazolium bromide (MTT) (Sigma Aldrich) was added to each well and the cells were incubated for $4 \mathrm{~h}$. The blue dye taken up by cells was dissolved in dimethyl sulfoxide, and the absorbance was measured with a microplate reader (Bio-Rad Laboratories, Hercules, CA, USA) at $540 \mathrm{~nm}$. All assays were run in triplicate.
Flow cytometry. Cells $\left(1 \times 10^{6}\right)$ were cultured in $100-\mathrm{mm}$ Petri dishes and treated with $4 \mu \mathrm{g} / \mathrm{ml} 5-\mathrm{FU}$ or $100 \mathrm{pg} / \mathrm{ml}$ DOC alone, in combination or in sequence. The cells were collected and fixed with $70 \%$ ethyl alcohol and kept at $-20^{\circ} \mathrm{C}$ until analyzed. Then, they were treated with propidium iodide $(40 \mu \mathrm{g} / \mathrm{ml})$ and RNase $\mathrm{A}(1 \mu \mathrm{g} / \mathrm{ml})$ at $37^{\circ} \mathrm{C}$ for $30 \mathrm{~min}$. Samples were kept on ice and the analysis of the sub G1 population was completed by measuring propidium iodide-stained DNA content with a Coulter ${ }^{\circledR}$ Epics $^{\circledR}$ XL-MCL cytometer (Beckman Coulter, Brea, CA, USA).

In vivo tumor growth assay. The tumorigenic potential of cancer cells was assessed by inoculation of cells into 5- to 6week-old female athymic BALB/c nude mice (Japan Clea Inc., Osaka, Japan). Cells $\left(5 \times 10^{6}\right)$ were inoculated subcutaneously into the backs of mice, 5 mice per group. When tumors reached $50-100 \mathrm{~mm}^{3}$ in volume, they were treated with sterile saline, $15 \mathrm{mg} / \mathrm{kg} 5-\mathrm{FU}$, and $10 \mathrm{mg} / \mathrm{kg}$ DOC by intraperitoneal (i.p.) injection. The treatment protocol of the six experimental groups of mice is shown in Fig. 2. Tumor volume and body weight of mice were measured 3 times a week. The tumor volumes were calculated by the formula: $0.5 \mathrm{x}$ largest diameter $\mathrm{x}$ (smallest diameter $)^{2}$. The mice were maintained under pathogen-free conditions and handled in accordance with the Guidelines for Animal Experimentation of Tokushima University.

RNA isolation and quantitative real-time reverse transcriptasepolymerase chain reaction (RT-PCR). When cells reached subconfluence in culture, they were treated with $4 \mu \mathrm{g} / \mathrm{ml} 5$-FU or $100 \mathrm{pg} / \mathrm{ml}$ DOC for 3, 6, 12, 24 or $48 \mathrm{~h}$. Total-RNA was extracted by using TRIzol ${ }^{\circledR}$ reagent (Invitrogen, Carlsbad, CA, USA). The cDNA was synthesized from total-RNA using the Advantage cDNA PCR kit ${ }^{\circledR}$ (Invitrogen). For quantitative real-time PCR, equal aliquots of cDNA were amplified with TaqMan universal $(50 \mu \mathrm{l})$ PCR master mix using the ABI prism 7000 Sequence Detection System (Applied Biosystems, Foster City, CA, USA) according to the manufacturer's instructions. The primer set and TaqMan probe used for the experiments were purchased from TaqMan gene expression assay systems (TS; Hs00426591_m1, DPD; Hs00559278_m1, and OPRT; Hs00165978_m1). Data were normalized using RT-PCR glyceraldehyde-3-phosphate dehydrogenase (GAPDH) primers (Applied Biosystems).

Western blot analysis. After cells were treated with $4 \mu \mathrm{g} / \mathrm{ml}$ $5-\mathrm{FU}$ or $100 \mathrm{pg} / \mathrm{ml}$ DOC alone, in combination or in sequence, they were collected and lysed. Mice treated with $15 \mathrm{mg} / \mathrm{kg}$ $5-\mathrm{FU}$ or $10 \mathrm{mg} / \mathrm{kg}$ DOC alone or in sequence were sacrificed on the 21st day, then tumors were collected from the mice and proteins were isolated from the tumors. Whole cell lysate was subjected to electrophoresis on $10 \%$ SDS-polyacrylamide gels and transferred to nitrocellulose membranes. Membranes were incubated with rabbit polyclonal antibodies against TS, DPD and OPRT (Taiho Pharma, Tokyo, Japan). After rinsing membranes, the antibodies were detected using a chemilumiescent western blotting detection system (Amersham, Tokyo, Japan) according to the manufacturer's instructions.

Statistical analysis. Statistical analysis was performed by MannWhitney U test; values of $\mathrm{p}<0.05$ were considered statistically significant. 
1. Control

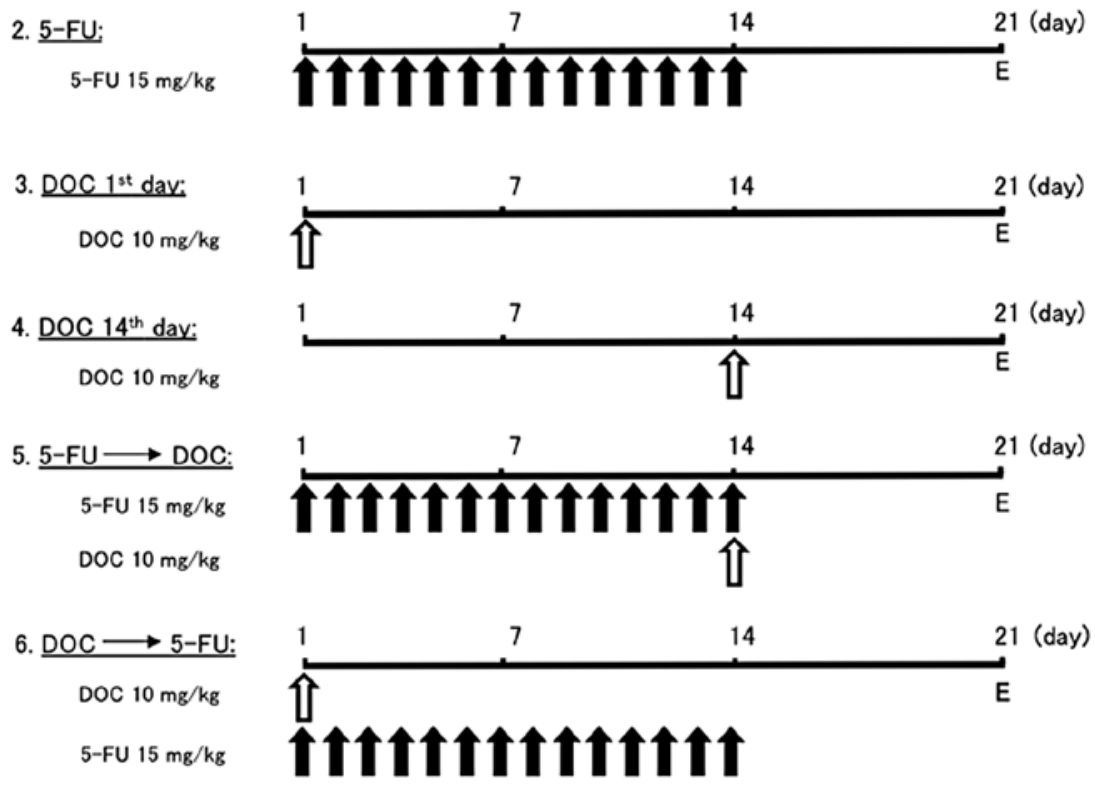

(E; evaluation of data)

Figure 2. The experimental protocol for the in vivo tumor growth assay. The groups were as follows: 1) control group, treated with sterile saline for 2 weeks; 2) 5-FU group, treated with 5-FU by i.p. for 14 days; 3) DOC 1st day group, DOC injected on day 1 of the treatment cycle; 4) DOC 14th day group, DOC injected on day 14; 5) 5-FU-DOC group, 5-FU injected for 14 days and DOC injected on day 14; and 6) DOC-5-FU group; DOC injected on day 1 and 5-FU injected for 14 days.

A

$\underline{B 88}$

$\underline{\text { CAL } 27}$
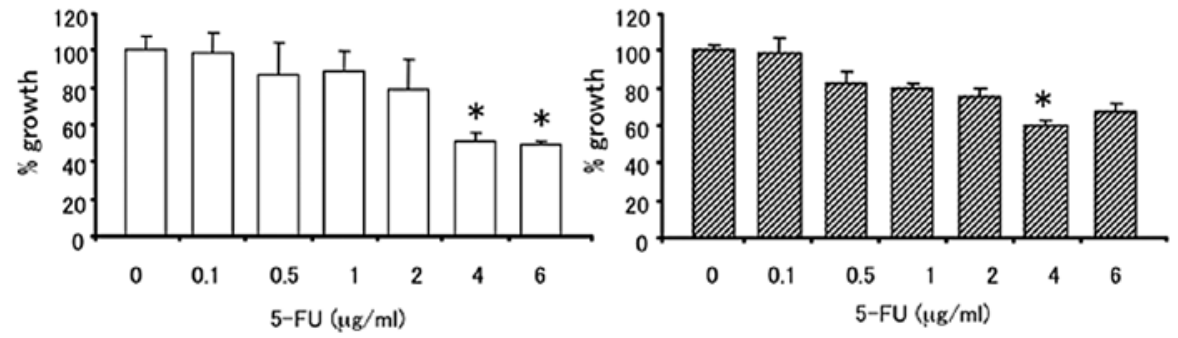

B

$\underline{B 88}$

CAL 27
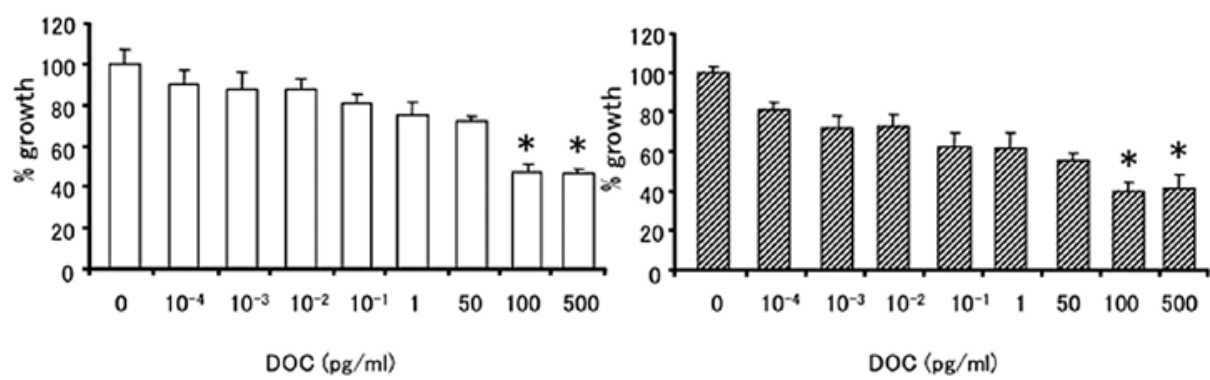

Figure 3. Growth inhibitory effects of 5-FU and DOC in vitro. Cells ( $3 \times 10^{3}$ cells per well) were seeded on 96 -well plates. Twenty-four hours later, the cells were treated with (A) 5-FU or (B) DOC for $24 \mathrm{~h}$. In vitro cell growth was evaluated by the MTT assay and reported as percentage growth. ${ }^{*} \mathrm{p}<0.05$.

\section{Results}

Growth inhibitory effects of sequential and combined treatment with 5-FU and DOC in oral cancer cells in vitro. The growth inhibitory effects of 5-FU and DOC on B88 and
CAL27 cells were analyzed by the MTT assay. Cells were treated with various concentrations of 5-FU or DOC alone for $24 \mathrm{~h}$ (Fig. 3) and $48 \mathrm{~h}$ (data not shown). 5-FU and DOC inhibited the growth of B88 and CAL27 cells in a dose-dependent manner. For sequential treatment, a concentration of $4 \mu \mathrm{g} / \mathrm{ml}$ 
$\underline{B 88}$

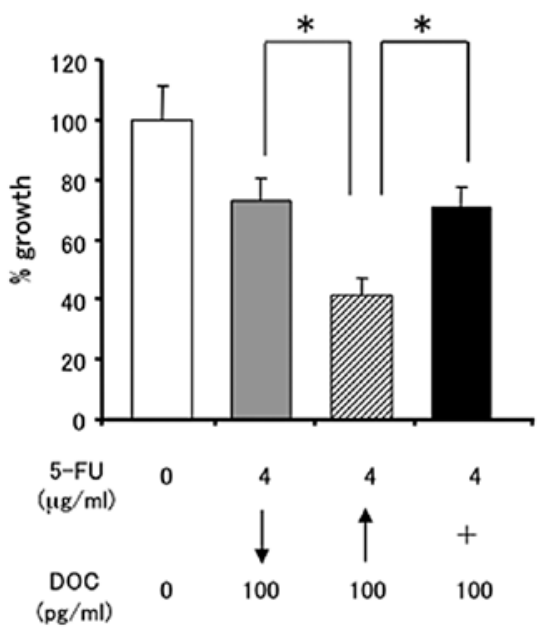

$\underline{\text { CAL27 }}$

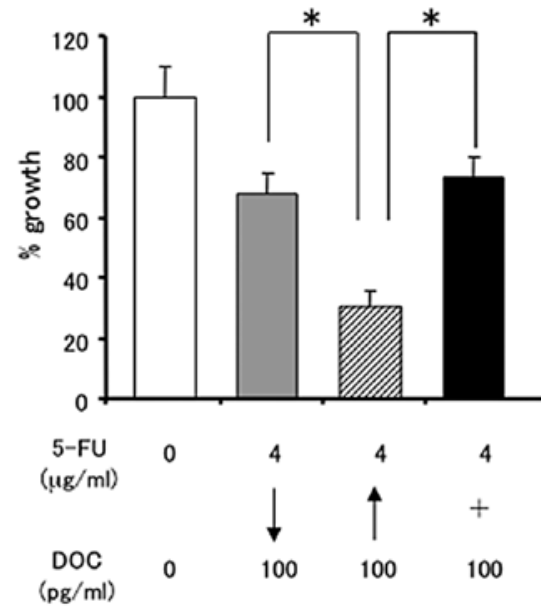

Figure 4. Growth suppression by sequential or combined treatment with 5-FU and DOC in B88 and CAL27 cells. The cells were untreated (for $48 \mathrm{~h}$ ), or treated with 5 -FU for $24 \mathrm{~h}$ followed by DOC for $24 \mathrm{~h}$, with DOC for $24 \mathrm{~h}$ followed by 5-FU for $24 \mathrm{~h}$, or with 5-FU and DOC for $48 \mathrm{~h}$. "p $<0.05$.

A
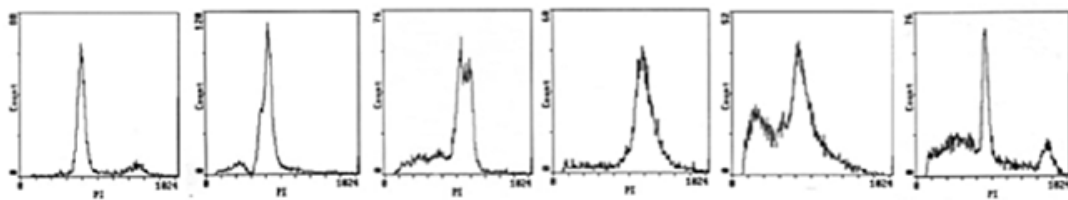

$5-\mathrm{FU}(\mu \mathrm{g} / \mathrm{ml}) \quad 0$

4

0

$\mathrm{DOC}(\mathrm{pg} / \mathrm{ml}) \quad 0$

0

100
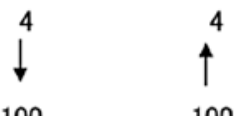

4

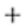

100

B

CAL 27

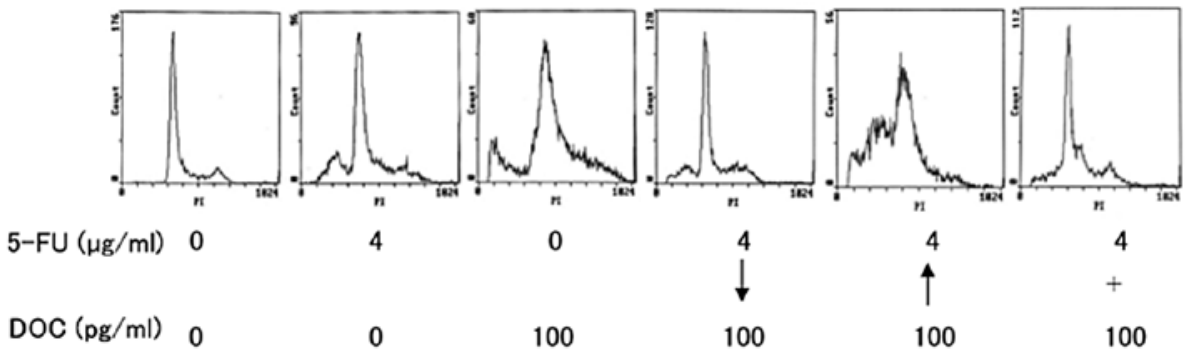

Figure 5. Flow cytometric analysis of treatment with 5-FU, DOC, in combination, or in sequence in (A) B88 and (B) CAL27 cells. The sub-G1 population of cell cycle shows apoptosis.

5-FU and $100 \mathrm{pg} / \mathrm{ml}$ DOC were selected. These concentrations showed a growth inhibitory rate of approximately $40-60 \%$ in both cancer cell lines (Fig. 3A and B). Thereafter, the effects of the sequential treatment with 5-FU and DOC were evaluated using following sequence. Cells were treated either with 5-FU ( $24 \mathrm{~h}$ ) followed by DOC ( $24 \mathrm{~h}$ ), with DOC followed by 5-FU, or with 5-FU and DOC at the same time (48 h). DOC followed by $5-\mathrm{FU}$ sequential treatment was more effective in inhibiting cancer cell growth than 5-FU followed by DOC treatment or combined treatment (Fig. 4). To investigate whether this enhanced cytotoxicity of sequential treatment was due to apoptosis, the sub G1 population of cancer cells was examined by flow cytometry (Fig. 5). B88 and CAL27 cells were treated with either 5-FU, DOC, or both of the drugs simultaneously or sequentially. The population of cells in the sub G1 phase was significantly increased in DOC followed by 5 -FU sequential treatment than 5-FU followed by DOC or combined treatment in both cancer cells (Fig. 5A and B).

Anti-tumor effects of sequential treatment with DOC and 5-FU on the human tumor xenografts in nude mice. To investigate the efficacy of the DOC followed by 5-FU sequence 
A

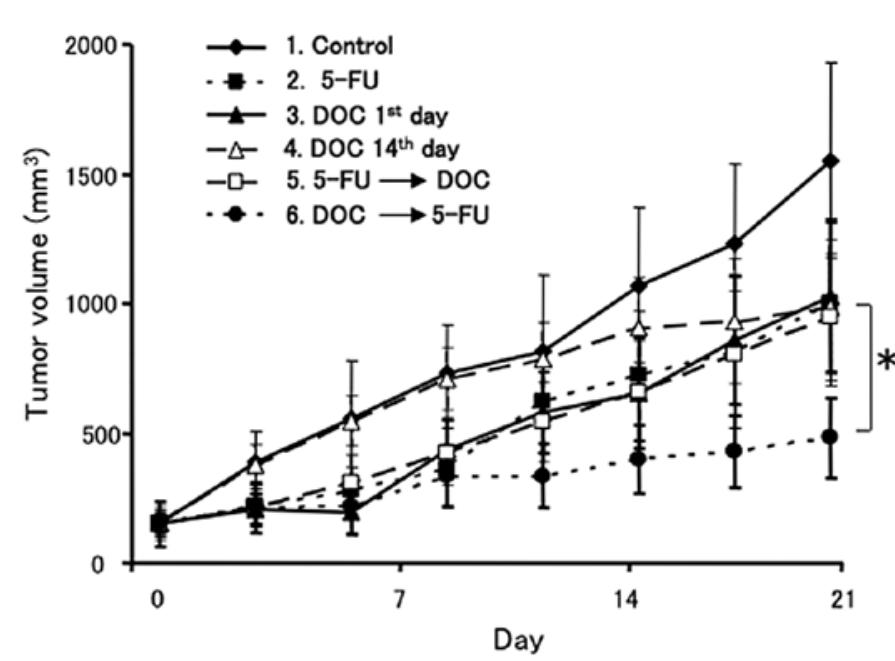

B

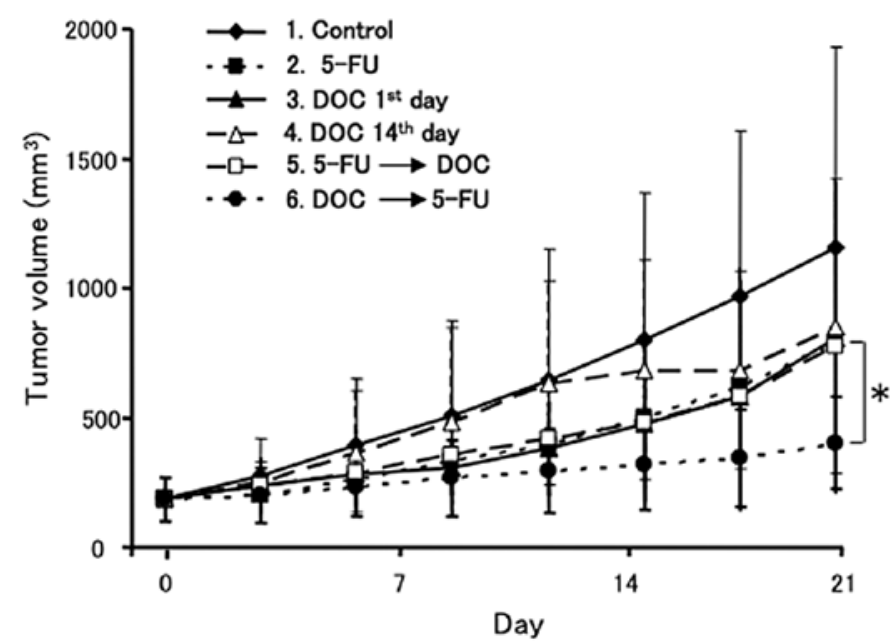

C

B88

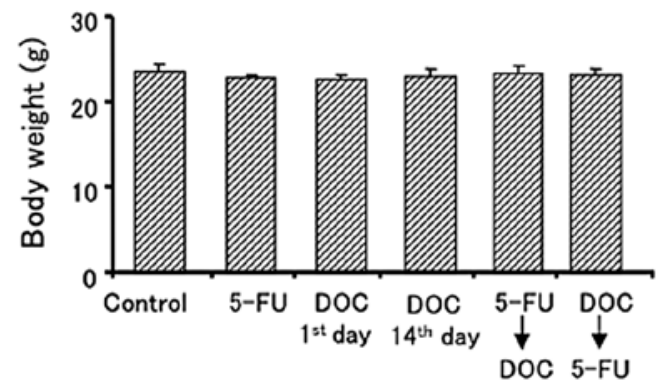

B

\section{CAL 27}

D
Control

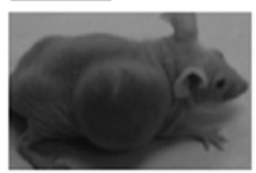

5-FU $\rightarrow$ DOC

*

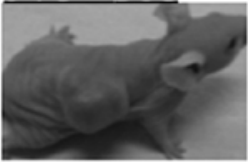

$\underline{\mathrm{DOC} \rightarrow 5-\mathrm{FU}}$

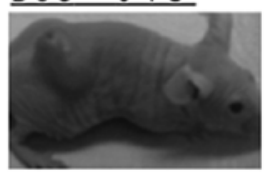

\section{$\underline{\text { Control }}$}

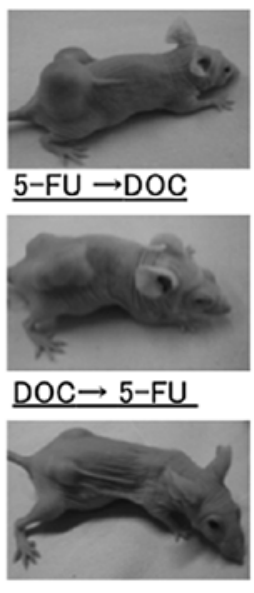

CAL 27

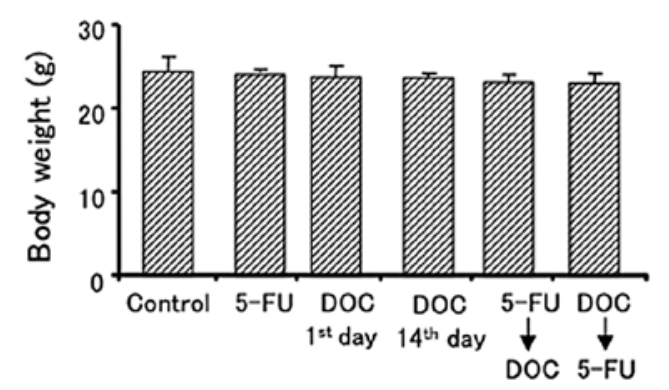

Figure 6. Anti-tumor effects of sequential treatment with 5-FU and DOC on tumor xenografts. B88 or CAL27 cells $\left(5 \times 10^{6}\right)$ were inoculated subcutaneously into the back of mice. When tumors reached $50-100 \mathrm{~mm}^{3}$ in volume, they were treated according to the protocol shown in Fig. 2. Tumor volume and the body weight of mice were measured 3 times a week. The tumor volumes were calculated by the following formula: $0.5 \mathrm{x}$ largest diameter $\mathrm{x}\left(\mathrm{smallest}\right.$ diameter) ${ }^{2}$ in $(\mathrm{A}) \mathrm{B} 88$ and (B) CAL27 xenografted mice. Right side shows the pictures of tumors in the untreated, 5-FU followed by DOC, and DOC followed by 5-FU groups. The body weight of (C) B88 and (D) CAL27 xenografted mice was measured on the 21st day. " $\mathrm{p}<0.05$.

in vivo, experiments with B88 and CAL27 tumor xenografts were performed. The treatment plan is shown in Fig. 2. Control mice were injected with saline (group 1). The mice in groups 2-6 were injected with $15 \mathrm{mg} / \mathrm{kg} 5-\mathrm{FU}$ alone, $10 \mathrm{mg} / \mathrm{kg}$ DOC alone, or sequential treatment with DOC and 5-FU. Fig. 6 shows the antitumor effects of the various treatment with DOC and/or 5-FU. In B88 tumor xenografts, DOC followed by 5-FU sequential treatment significantly reduced tumor growth 
A

$\underline{\text { TS }}$

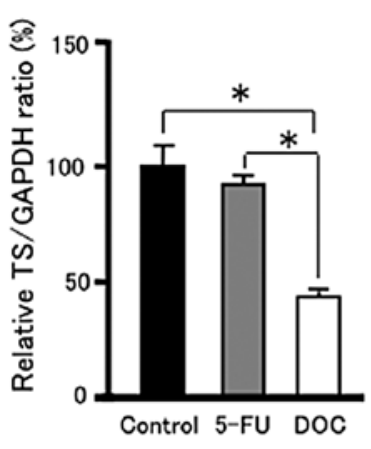

B

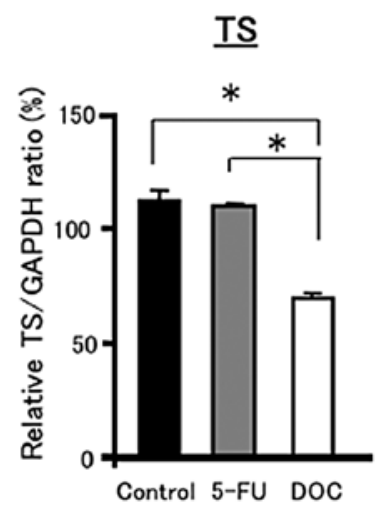

$\underline{B 88}$

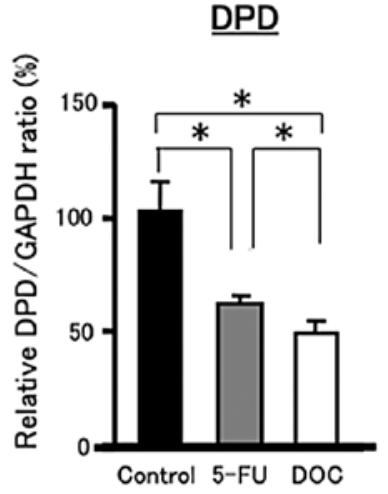

$\underline{\text { CAL } 27}$

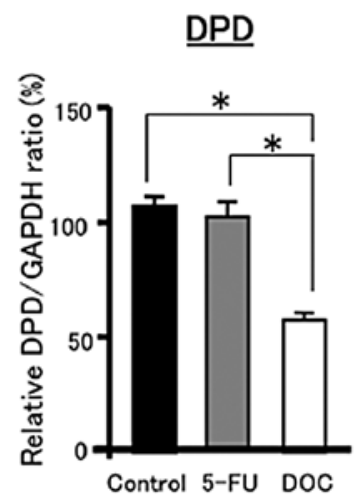

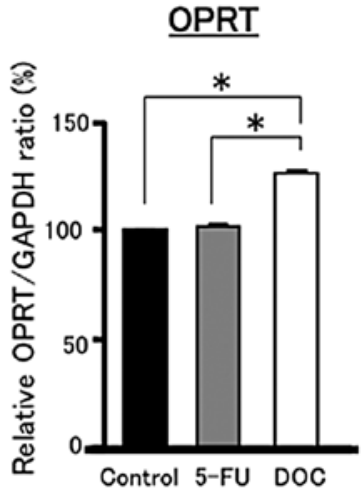

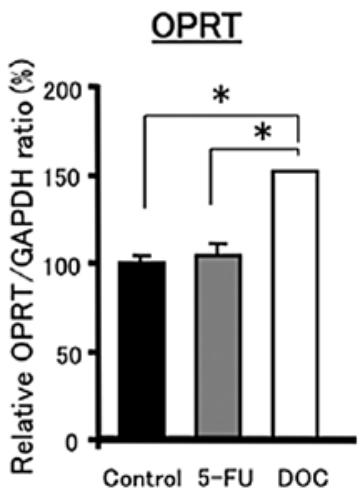

Figure 7. Effects of treatment with 5-FU or DOC on the mRNA expression of TS, DPD, and OPRT in (A) B88 and (B) CAL27 cells. The data are shown as the ratio of the GAPDH-normalized fold change in the PCR product in control cells. The results are representative of the mean of three independent data. " $p<0.05$.

compared to the control, 5-FU followed by DOC or other treatment groups (Fig. 6A). However, there was no significant difference between DOC 1st day (group 3) and DOC 14th day (group 4). The results for the CAL27 tumor xenografts were similar to those for the B88 tumors (Fig. 6B). In addition, drug toxicity did not cause carcass weight loss in any of the treated mice in these experiments (Fig. 6C and D). Altogether, these results showed that DOC followed by 5-FU was the most effective treatment sequence in vivo.

Effects of 5-FU or DOC treatment on the expression of TS, $D P D$ and $O P R T$. To further identify the mechanisms underlying the enhanced growth inhibition by the sequential treatment, DOC followed by 5-FU, the expression levels of 5-FU metabolic enzymes, TS, DPD and OPRT were examined in cancer cells. These expression profiles were determined by real-time RT-PCR and western blot analysis, following treatment of cancer cells with 5-FU or DOC alone, in combination or in sequence.

Fig. 7 shows the mRNA expression levels of TS, DPD and OPRT in B88 and CAL27 cells after $12 \mathrm{~h}$ of treatment with $4 \mu \mathrm{g} / \mathrm{ml} 5$-FU or $100 \mathrm{pg} / \mathrm{ml}$ DOC alone. There were no significant differences in TS expression between the control and 5-FU treatment. However, DOC treatment significantly decreased the expression of TS compared to the control and 5-FU treatment in B88 and CAL27 cells. The expression of DPD was also reduced by DOC treatment compared to the control and 5-FU treatment in both cell lines. In contrast, DOC significantly increased the expression of OPRT compared to the control and 5-FU treatment in both cell lines.

To examine the expression of TS, DPD and OPRT at the protein level, western blot analysis was performed. As shown in Fig. 8A, the expression of TS, DPD and OPRT after 5-FU or DOC treatment in B88 and CAL27 cells was examined. The expression of TS and DPD was reduced by the treatment with DOC compared to the control and 5-FU treatment, whereas, the expression of OPRT was slightly increased by DOC treatment (Fig. 8A). Fig. 8B shows the expression of TS, DPD and OPRT in B88 and CAL27 cells after $24 \mathrm{~h}$ of 5-FU and DOC combined and sequential treatment. The expression of TS and DPD was downregulated by DOC followed by 5-FU compared to 5-FU followed by DOC or combined treatment. OPRT expression was also upregulated by DOC followed by $5-\mathrm{FU}$ in both cell lines (Fig. 8B).

To investigate the expression of TS, DPD and OPRT in vivo, western blot analysis was performed with tumors extirpated from mice used in the xenograft experiment shown in Figs. 2 and 6. As shown in Fig. 9, DOC followed by 5-FU downregulated the expression of TS and DPD and upregulated the expression of OPRT compared to 5-FU followed by DOC or 5-FU alone. These results show that downregulation of TS and 
A
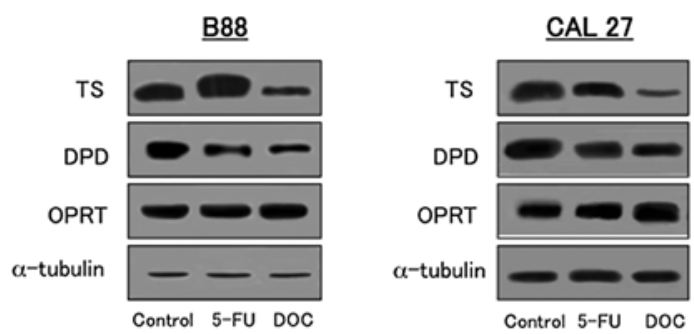

B

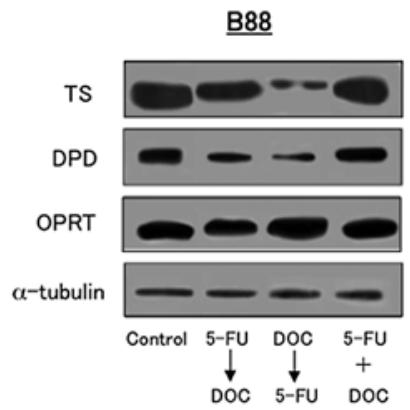

Figure 8. Effects of treatment with 5-FU and/or DOC on the protein expression of TS, DPD, and OPRT in B88 and CAL27 cells by western blot analysis. The cancer cells were treated with 5-FU or DOC alone, (A) in sequence or (B) in combination. Whole cell fractions were subjected to western blot analysis.

$\underline{B 88}$

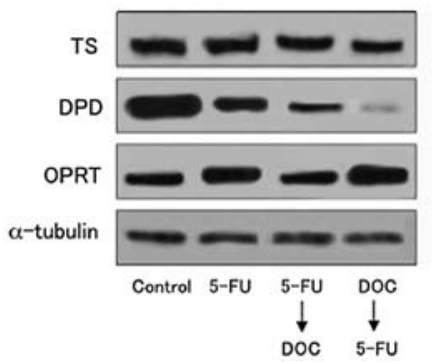

$\underline{\text { CAL } 27}$

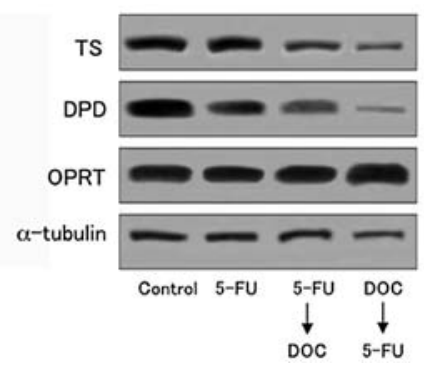

Figure 9. Effects of treatment with 5-FU and/or DOC on the protein expression of TS, DPD, and OPRT in mouse tumors. Tumors were collected from B88 and CAL27 xenografted mice on the 21st day. Proteins isolated from the tumors were subjected to western blot analysis.

DPD expression and upregulation of OPRT expression were induced by DOC treatment in vitro and in vivo.

\section{Discussion}

In this study, the anti-tumor effects of sequential treatment with DOC and 5-FU against OSCC were investigated. It was clearly demonstrated that DOC followed by 5-FU treatment more effectively inhibited tumor growth in vitro and in vivo compared to 5-FU followed by DOC treatment. Furthermore, to elucidate the mechanisms underlying the enhanced growth inhibitory effect of DOC followed by 5-FU, the expression of the 5-FU metabolic enzymes TS, DPD, and OPRT was examined. Thus, DOC downregulated the expression of TS and DPD and upregulated OPRT expression in cancer cells, and these alterations of 5-FU

metabolic enzyme expression could enhance anti-tumor effects of 5-FU in DOC followed by 5-FU treatment.

5-FU metabolic enzymes regulate the anti-tumor efficacy of 5-FU (9-11). High expression of TS and DPD in tumors has been associated with its resistance to 5-FU (19-21). TS, of these enzymes, is the most important regulator of the sensitivity of cancer cells to 5-FU. TS plays important roles in cellular proliferation and growth, catalyzing the methylation of FdUMP to deoxythymidine monophosphate (dTMP), an essential precursor for DNA synthesis (22). Therefore, TS inhibiting drugs could augment the efficacy of 5-FU. The present study demonstrated that the expression of TS protein and mRNA was decreased by DOC, however, the expression of TS protein was enhanced by $5-\mathrm{FU}$ in $\mathrm{B} 88$ cells. The precise mechanisms responsible for the induction of TS expression by 5-FU and downregulation of TS expression by DOC are not fully understood (19). It was reported that the transcriptional activator E2F1, a cell cycle regulatory protein forming complexes with $\mathrm{Rb}$, encodes a representative transcriptional enzyme that transcribes the messages of TS (23). In addition, several studies using cDNA microarray demonstrated that the expression of $\mathrm{E} 2 \mathrm{~F} 1$ and $\mathrm{Rb}$ was decreased by DOC in head and neck squamous cell carcinoma (HNSCC) $(24,25)$. Therefore, DOC could lead to suppression of TS expression via inhibition of E2F1/Rb expression. On the other hand, DPD expression was also downregulated by DOC. However, the mechanisms behind this downregulation of DPD have not been fully analyzed. Recently, Ukon et al (26) reported that activation of protein (AP)-1 accelerated DPD gene transcription in gastric cancer cells. In addition, Yoo et al $(24,25)$ reported that DOC downregulated the expression of c-Jun N-terminal kinase (JNK) and phosphorylated JNK in HNSCC cells. Therefore, DPD expression could be downregulated by DOC via inhibition of the JNK-AP-1 pathway.

It was reported that combined treatment with DOC and 5-FU had synergistic inhibitory effects on the growth of breast and gastric cancer cells (16), however, sequential treatment with DOC and 5-FU was not examined. In the present study, the effects of administration sequence on drug efficacy with DOC and 5-FU were evaluated. In in vivo study, it is clearly demonstrated that DOC followed by 5 -FU treatment more effectively inhibited tumor growth compared to 5-FU followed by DOC. But, the possibility was considered that this result was affected by the different timing of the DOC injection into the mice in DOC followed by 5-FU and 5-FU followed by DOC treatment. Thus, DOC was injected on day 1 in DOC followed by $5-\mathrm{FU}$ treatment, whereas on day 14 in 5 -FU followed by DOC treatment. It means that the enhanced anti-tumor effect of DOC followed by 5-FU may be caused by the difference in duration of DOC action. However, there was no significant difference in tumor growth rates between DOC 1st and DOC 14th groups on the evaluated day. Therefore, this result suggested that timing of the DOC injection did not appear to affect the anti-tumor effect of those two sequential treatments. Thus, the enhanced efficacy of DOC followed by 5-FU could be caused by the effect of DOC, which directly regulated 5-FU metabolic enzymes.

The mechanisms underlying the enhanced growth inhibitory effect of DOC followed by 5-FU, compared to 5-FU followed by DOC could be explained by considering two possibilities. One is that DOC affects the expression of 5-FU metabolic enzymes 
or 5-FU regulated genes. The other is that 5-FU provides the effects on DOC regulated genes. Yoo et al (25) reported that DOC induced the expression of the cell cycle regulator proteins p19 and cyclin-dependent kinase 2, but reduced the expression of cyclin A, B, C, D2 and D3, E2F1 and bcl-2. Among these genes, the overexpression of bcl-2 is correlated with upregulation of TS expression and resistance of colorectal cancer cells to DOC (27). On the other hand, resistance to DOC also appears to be caused by the high expression of P-glycoproteins, thioredoxin, and ribophorin 2 (RPN2) (19) and by the low expression of p27 (19,28). However, effects of 5-FU on the expression of DOC resistance related genes, RPN2, P-glycoprotein, bcl-2, and DOC induced genes were not examined in this study. Studies on effects of 5-FU on genes related to DOC resistance will be important to understand the mechanisms of DOC and 5-FU sequential treatment.

A more effective chemotherapy based on 5-FU and DOC may be developed by using various modulators for metabolic enzymes of 5-FU and resistance related genes of DOC. Several pathways could be considered, including the phosphatidylinositol 3-kinases (PI3K)-Akt mammalian target of rapamycin (mTOR) pathway, which is related with various types of malignancies (28). It has been reported that activation of the PI3K-Akt-mTOR pathway induces TS expression and could be responsible for the incomplete response of cancer for DOC and 5-FU (28,29). Moreover, Shigematsu et al (28) reported that an mTOR inhibitor, rapamycin, downregulated the expression of TS and showed enhanced anti-tumor effects in combination with DOC and 5-FU in gastric cancer. The TS inhibitors TOM and Thymitaq, and the DPD inhibitor eniluracil, have been used in combination with 5-FU for their enhanced anti-tumor effects against various types of cancers (29-31). Insufficient inhibition of TS and DPD could be the cause of poor outcomes of 5-FU and DOC based treatments, therefore, novel combinations of TS or DPD inhibitors with 5-FU and DOC could provide important new opportunities for improving the clinical outcome for oral cancer patients. Moreover, the overexpression of bcl-2 and constitutive activation of $N F-\kappa B$ have been reported to cause the resistance to 5-FU and DOC in cancer cells (32-34). Therefore, understanding the effects of these modulators on the efficacy of 5-FU and DOC treatment, and inhibition of the signaling pathways related to bcl- 2 or $\mathrm{NF}-\kappa \mathrm{B}$ would facilitate the development of new therapeutic strategies based on 5-FU and DOC.

In conclusion, this study clearly showed that sequential treatment with DOC followed by 5-FU more effectively inhibited the tumor growth of oral cancer cells. The mechanisms underlying the growth inhibitory effect of DOC followed by 5-FU sequential treatment could be downregulation of TS and DPD expression, and upregulation of OPRT expression induced by DOC treatment. Thereby, anti-tumor effect of 5-FU could be enhanced in DOC followed by 5-FU treatment. These findings demonstrated that sequential treatment with DOC followed by 5-FU can be more effective for the patients with OSCC than that with 5-FU followed by DOC.

\section{Acknowledgements}

This work was supported in part by Grants-in-Aid for young Scientists (B)(23792351).

\section{References}

1. Azuma M, Harada K, Suprianto, Tamatani T, Motegi K, Ashida Y and Sato M: Potentiation of induction of apoptosis by sequential treatment with cisplatin followed by 5-fluorouracil in human oral cancer cells. Int J Oncol 24: 1449-1455, 2004.

2. Inagi K, Takahashi H, Okamoto M, Nakayama M, Makoshi T and Nagai H: Treatment effects in patients with squamous cell carcinoma of the oral cavity. Acta Otolaryngol (Suppl) 547: 25-29, 2002.

3. Shingaki S, Takada M, Sasai K, Bibi R, Kobayashi T, Nomura T and Saito C: Impact of lymph node metastasis on the pattern of failure and survival in oral carcinomas. Am J Surg 185: 278-284, 2003.

4. LoTempio MM, Veena MS, Steele HL, Ramamurthy B, Ramalingam TS, Cohen AN, Chakrabarti R, Srivatsan ES and Wang MB: Curcumin suppresses growth of head and neck squamous cell carcinoma. Clin Cancer Res 11: 6994-7002, 2005.

5. Janinis J, Papadakou M, Panagos G, Panousaki A, Georgoulias V, Hatzidaki D, Lefantzis D and Dokianakis G: Sequential chemoradiotherapy with docetaxel, cisplatin and 5 -fluorouracil in patients with locally advanced head and neck cancer. Am J Clin Oncol 24: 227-231, 2001.

6. Schrijvers D, Herpen CV, Kerger J, Joosens E, Laer CV, Awada A, Weyngaert VD, Nguyen H, Bouder CL, Castelijns JA, Kaanders J, Mulder PD and Vermorken JB: Docetaxel, cisplatin and 5-fluorouracil in patients with locally advanced unresectable head and neck cancer: a phase I-II feasibility study. Ann Oncol 15: 638-645, 2004.

7. Yamamoto S, Kurebayashi J, Kurosomi M, Kunisue H, Otsuki T, Tanaka K and Sonoo H: Combined effects of docetaxel and fluoropyrimidines on tumor growth and expression of interleukin-6 and thymidine phosphorylase in breast cancer xenografts. Cancer Chemother Pharmacol 48: 233-238, 2001.

8. Yoshida K, Ninomiya M, Takakura N, Hirabayashi N, Takiyama W, Sato Y, Todo S, Terashima M, Gotoh M, Sakamoto $\mathrm{J}$ and Nishiyama M: Phase II study of docetaxel and $\mathrm{S}-1$ combination therapy for advanced or recurrent gastric cancer. Clin Cancer Res 12: 3402-3407, 2006.

9. Ishikawa M, Miyauchi T and Kashiwagi Y: Clinical implications of thymidylate synthetase, dihydropyrimidine dehydrogenase and ortate phosphoribosyl transferase activity level in colorectal carcinoma following radical resection and administration of adjuvant 5-FU chemotherapy. BMC Cancer 8: 188-194, 2008.

10. Ando T, Ishiguro H, Kuwabara Y, Kimura M, Mitsui A, Sugito N, Mori R, Ogawa R, Katada T and Fujii Y: Relationship between expression of 5-fluorouracil metabolic enzymes and 5 -fluorouracil sensitivity in esophageal carcinoma cell lines. Dis Esophagus 21: 15-20, 2008.

11. Ichikawa W, Uetake H, Shirota Y, Yamada H, Nishi N, Nihei Z, Sugihara K and Hirayama R: Combination of dihydropyrimidine dehydrogenase and thymidylate synthase gene expressions in primary tumors as predictive parameters for the efficacy of fluoropyrimidine-based chemotherapy for metastatic colorectal cancer. Clin Cancer Res 9: 786-791, 2003.

12. Taomoto J, Yoshida K, Wada Y, Tanabe K, Konishi K, Tahara H and Fukushima M: Overexpression of the ortate phosphoribosyl transferase gene enhances the effect of 5-fluorouracil on gastric cancer cell lines. Oncology 70: 458-464, 2006.

13. Sakakura K, Chikamatsu K, Shino M, Sakurai T and Furuya N: Expression of thymidylate synthase and dihydropyrimidine dehydrogenase in oral squamous cell carcinoma: possible markers as predictors of clinical outcome. Acta Otolaryngol 126: 1295-1302, 2006.

14. Kobayashi H, Koike T, Nakatsuka A, Kurita H, Sagara J, Taniguchi S and Kurashina K: Dihydropyrimidine dehydrogenase expression predicts survival outcome and chemosensitivity to 5-fluorouracil in patients with oral squamous cell carcinoma. Oral Oncol 41: 38-47, 2005.

15. Catimel G, Verwii J, Mattijssen V, Hanauska A, Piccart M, Wanders J, Franklin H, Le Bail N, Clavel M and Kaye SB: Docetaxel (taxotere): an active drug for treatment of patients with advanced squamous cell carcinoma of the head and neck. EORTC Early Clinical Trials Group. Ann Oncol 5: 533-537, 1994.

16. Wada Y, Yoshida K, Suzuki T, Mizuiri H, Konishi K, Ukon K, Tanabe K, Sakata Y and Fukushima M: Synergistic effects of docetaxel and S-1 by modulating the expression of metabolic enzymes of 5-fluorouracil in human gastric cancer cell lines. Int J Cancer 119: 783-791, 2006. 
17. Ravdin PM, Burris HA, Cook G, Eisenberg P, Kane M Bierman WA, Mortimer J, Genevois E and Bellet RE: Phase II trial of docetaxel in advanced anthracycline-resistant or anthracenedione-resistant breast cancer. J Clin Oncol 13: 2879-2885, 1995.

18. Tamatani T, Azuma M, Ashida Y, Yoshida $\mathrm{H}$ and Sato $\mathrm{M}$ Enhanced radiosensitization and chemosensitization in NF- $\kappa \mathrm{B}$ suppressed human oral cancer cells via the inhibition of $\gamma$-irradiation- and 5-FU-induced production of IL-6 and IL-8 Int J Cancer 108: 912-921, 2004.

19. Honma K, Koizumi K, Takeshita F, Yamamoto Y, Yoshida T, Nishio K, Nagahara S, Kato K and Ochiya T: RPN2 gene confers docetaxel resistance in breast cancer. Nat Med 14: 939-948, 2008.

20. Longley DB, Harkin DP and Johnston PG: 5-fluorouracil: mechanisms of action and clinical strategies. Nat Rev Cancer 3: 330-338, 2003.

21. Van Kuilenburg AB: Dihydropyrimidine dehydrogenase and the efficacy and toxicity of 5-fluorouracil. Eur J Cancer 40 939-950, 2004

22. Ceppi P, Volante M, Ferrero A, Righi L, Rapa I, Rosas R, Berruti A, Dogliotti L, Scagliotti GV and Papotti $M$; Thymidylate synthase expression in gastroenteropancreatic and pulmonary neuroendocrine tumors. Clin Cancer Res 14 1059-1064, 2008

23. Yoshinare K, Kubota T, Watanabe M, Wada N, Nishibori H, Hasegawa H, Kitajima M, Takechi T and Fukushima M: Gene expression in colorectal cancer and in vitro chemosensitivity of 5-fluorouracil: a study of 88 surgical specimen. Cancer Sci 94 633-638, 2003

24. Yoo GH, Lin HS, Iskander AJ, Piechocki MP, Oliver J, Kewson D, Lonardo, F, Tainsky MA, Kim HR, Kim H and Ensley JF: Docetaxel associated pathways in cisplatin resistant head and neck squamous cell carcinoma: a pilot study. Laryngoscope 115: 1938-1946, 2005.

25. Yoo GH, Piechocki MP, Ensley JF, Nguyen T, Oliver J, Meng H, Kewson D, Shibuya TY, Lonardo F and Tainsky MA: Docetaxel induced gene expression patterns in head and neck squamous cell carcinoma using cDNA microarray and powerblot. Clin Cancer Res 8: 3910-3921, 2002.

26. Ukon K, Tanimoto K, Shimokuni T, Noguchi T, Hiyama K, Tsujimoto H, Fukushima M, Toge T and Nishiyama M: Activator protein accelerates dihydropyrimidine dehydrogenase gene transcription in cancer cells. Cancer Res 65: 1055-1062, 2005.
27. Bendardaf R, Ristamäki R, Syrjänen K and Pyrhönen S: Bcl-2 expression significantly correlates with thymidylate synthase expression in colorectal cancer patients. World J Gastroenterol 14: 6218-6223, 2008

28. Shigematsu H, Yoshida K, Sanada Y, Osada S, Takahashi T, Wada Y, Konishi K, Okada M and Fukushima M: Rapamycin enhances chemotherapy-induced cytotoxicity by inhibiting the expressions of TS and ERK in gastric cancer cells. Int J Cancer 126: 2716-2725, 2010.

29. Chang JC, Wooten EC, Tsimelzon A, Hilsenbeck SG, Gutierrez MC, Tham YL, Kalidas M, Elledge R, Mohsin S, Osborne CK, Chamness GC, Allred DC, Lewis MT, Wong H and $\mathrm{O}^{\prime}$ Connell P: Patterns of resistance and incomplete response to docetaxel by gene expression profiling in breast cancer patients. J Clin Oncol 23: 1169-1177, 2005.

30. Ford HER, Mitchell F, Cunningham D, Farrugia DC, Hill ME, Rees C, Calvert AH, Judson IR and Jackman AL: Patterns of elevation of plasma 2'-deoxyuridine, a surrogate marker of thymidylate synthase (TS) inhibition, after administration of two different schedules of 5-fluorouracil and the specific TS inhibitors raltitrexed (Tomudex) and ZD93311. Clin Cancer Res 8: 103-109, 2002.

31. Ahmed FY, Johnston SJ, Cassidy J, Kelly T, Binnie N, Murray GI, Gennip AH, Abeling NG, Knight S and McLeod HL: Eniluracil treatment completely inactivates dihydropyrimidine dehydrogenase in colorectal tumours. J Clin Oncol 17: 2439-2445, 1999.

32. Mirjolet JF, Heyob MB, Didelot C, Peyrat JP, Abecassis J, Millon R and Merlin JL: Bcl-2/Bax protein ratio predicts 5-fluorouracil sensitivity independently of p53 status. Br J Cancer 83: 1380-1386, 2000.

33. Domenech JD, Oliva C, Rovira A, Servat JC, Bosch M, Filella X, Montagut C, Tapia M, Campas C, Dang L, Rolfe M, Ross JS, Gascon P, Albanell J and Mellado B: Interleukin 6 , a nuclear factor- $\kappa \mathrm{B}$ target, predicts resistance to docetaxel in hormone-independent prostate cancer and nuclear factor $-\kappa \mathrm{B}$ inhibition by PS-1145 enhances docetaxel antitumor activity. Clin Cancer Res 12: 5578-5586, 2006.

34. Li J, Minnich DJ, Camp ER, Brank A, MacKay S and Hochwald SN: Enhanced sensitivity to chemotherapy in esophageal cancer through inhibition of NF-kB. J Surg Res 132: $112-120,2006$ 